\title{
Human papillomavirus in oropharyngeal cancer in Canada: analysis of 5 comprehensive cancer centres using multiple imputation
}

\author{
Steven Habbous MSc, Karen P. Chu MD, Harold Lau MD, Melissa Schorr MD, Mathieos Belayneh BMSc, \\ Michael N. Ha PhD MD, Scott Murray MD, Brian O'Sullivan MB, Shao Hui Huang MRT(T) MD, \\ Stephanie Snow MD, Matthew Parliament MD, Desiree Hao MD, Winson Y. Cheung MPH MD, Wei Xu PhD, \\ Geoffrey Liu MSc MD
}

Cite as: CMAJ 2017 August 14;189:E1030-40. doi: 10.1503/cmaj.161379

\begin{abstract}
BACKGROUND: The incidence of oropharyngeal cancer has risen over the past 2 decades. This rise has been attributed to human papillomavirus (HPV), but information on temporal trends in incidence of HPV-associated cancers across Canada is limited.
\end{abstract}

METHODS: We collected social, clinical and demographic characteristics and p16 protein status ( $\mathrm{p} 16$-positive or p16-negative, using this immunohistochemistry variable as a surrogate marker of HPV status) for 3643 patients with oropharyngeal cancer diagnosed between 2000 and 2012 at comprehensive cancer centres in British Columbia (6 centres), Edmonton, Calgary, Toronto and Halifax. We used receiver operating characteristic curves and multiple imputation to estimate the p16 status for missing values. We chose a best-imputation probability cut point on the basis of accuracy in samples with known p16 status and through an independent relation between $\mathrm{p} 16$ status and overall survival. We used logistic and Cox proportional hazard regression.

RESULTS: We found no temporal changes in p16-positive status initially, but there was significant selection bias, with p16 testing significantly more likely to be performed in males, lifetime never-smokers, patients with tonsillar or base-of-tongue tumours and those with nodal involvement $(p<0.05$ for each variable). We used the following variables associated with p16-positive status for multiple imputation: male sex, tonsillar or base-of-tongue tumours, smaller tumours, nodal involvement, less smoking and lower alcohol consumption ( $p<0.05$ for each variable). Using sensitivity analyses, we showed that different imputation probability cut points for p16-positive status each identified a rise from 2000 to 2012, with the best-probability cut point identifying an increase from $47.3 \%$ in 2000 to $73.7 \%$ in $2012(p<0.001)$.

INTERPRETATION: Across multiple centres in Canada, there was a steady rise in the proportion of oropharyngeal cancers attributable to HPV from 2000 to 2012.
$\mathrm{T}$ he incidence of oropharyngeal cancer has increased over the past 2 decades. ${ }^{1-3}$ This rise has largely been attributed to oncogenic human papillomavirus (HPV), yet many population-based studies have been limited to using anatomic subsites as an indicator for "HPV-associated" cancer. ${ }^{4-7}$ Patients with HPV-positive oropharyngeal cancer have consistently had better survival than those with HPV-negative oropharyngeal cancer. ${ }^{8}$ Because of the high rates of response to treatment, therapy that is less intense may reduce treatmentrelated toxicity without detrimentally affecting outcomes. ${ }^{9,10}$ On this basis, HPV-positive oropharyngeal cancer is considered a distinct form of head and neck cancer. ${ }^{11}$ To evaluate the changing burden of HPV-positive oropharyngeal cancer in Canada, its changing incidence should be estimated accurately.

Systematic testing of all available oropharyngeal tumours for HPV status has become routine practice in some centres, but not across Canada. Selected testing was the norm from 2000 to 2012. Failing to account for testing selection bias can result in inaccurate estimates of HPV positivity. In this study, we attempted to address this knowledge gap by using data obtained from several major centres across Canada to analyze all patients with oropharyngeal cancer and assess rates of HPV-associated cancer. 


\section{Methods}

\section{Patient population}

Adult patients 18 years of age or older with squamous cell oropharyngeal cancer diagnosed from 2000 to 2012 were included (International Statistical Classification of Diseases and Related Health Problems, 10th revision [ICD-10], codes C01, C05.1, C05.2 and (10). To minimize the potential for selection bias, we included all patients with oropharyngeal cancer and not just those who had HPV testing results. Following an email request for centres across Canada to join the study, data were supplied by 5 Canadian cancer organizations: the Princess Margaret Cancer Centre (Toronto); the British Columbia Cancer Agency, which consists of 6 regional cancer centres; the Tom Baker Cancer Centre (Calgary), the Cross Cancer Institute (Edmonton) and the Nova Scotia Cancer Centre (Halifax; at the time of the study, this centre covered all of Nova Scotia). Systematic (routine) reflex HPV testing started in 2008 in Calgary, 2009 in Halifax, mid-2009 in Toronto, 2010 in Edmonton and 2015 in British Columbia.

\section{Data collection}

We developed a single prospective, electronic database with an associated data dictionary, based on an existing database, ${ }^{1}$ to allow all centres to capture information uniformly. We reviewed electronic medical records and data from institutional registries to obtain clinical and demographic characteristics: age at diagnosis, sex, marital status, body mass index, year of diagnosis, anatomic subsite, clinical staging, primary treatment, smoking status and alcohol consumption (as defined previously ${ }^{1}$ ). The frequency of missing data is presented in Appendix 1 (available at www.cmaj.ca/lookup/suppl/doi:10.1503/ cmaj.161379/-/DC1).

p16 protein immunohistochemistry was used as a surrogate for HPV status, and results were dichotomized as p16-positive or p16-negative. ${ }^{12-15}$ Details on p16 testing can be found in Appendix 2 (available at www.cmaj.ca/lookup/suppl/doi :10.1503/cmaj.161379/-/DC1). p16 immunohistochemistry is a validated method to measure HPV status in oropharyngeal cancer. ${ }^{12,13,16}$

\section{Statistical analysis}

We used multivariable logistic regression to determine which factors were associated with p16 testing (tested v. untested) and p16 status among those tested (p16-positive v. p16-negative); these factors would form the basis of a predictive model used as a first step in imputation. We calculated odds ratios (ORs) with 95\% confidence intervals ( $\mathrm{Cls}$ ) for each factor. We then developed a predictive model based on the factors associated with p16 status, in preparation for multiple imputation of missing p16 data. We assessed the ability of the logistic regression model to predict p16 status using receiver operating characteristic curves, and compared areas under the curve between models using the C statistic (with 95\% Cl).

We performed overall survival analyses using Cox proportional hazard regression, presented with hazard ratios (HRs) and Kaplan-Meier plots. All multivariable models included the fol- lowing covariables unless otherwise specified: age at diagnosis, sex, anatomic subsite (tonsil, base of tongue, other), tumour classification (T1-T4), nodal classification (N0-N3), smoking status (current, former, never), smoking pack-years and alcohol consumption (none/light, moderate/heavy). We stratified the data by the city or province of diagnosis, where appropriate.

\section{Multiple imputation}

Because we did not wish to limit our analysis to only those patients with results from HPV testing, we used multiple imputation to derive HPV status for patients with missing test results. Multiple imputation was conducted using the variables that resulted in the best predictive model for p16 status (using the $C$ statistics described above). Following 100 imputations, the number of times that each patient was classified as p16-positive was referred to as the probability of p16-positive status or $\operatorname{Pr}(\mathrm{p} 16+)$. To classify patients as $\mathrm{p} 16$-positive or p16-negative, we defined a cut point of $\operatorname{Pr}(\mathrm{p} 16+)$ using leaveone-out cross-validation and survival analyses (an overview of the method is presented in Appendix 3, available at www.cmaj. ca/lookup/suppl/doi:10.1503/cmaj.161379/-/DC1). The distribution of $\operatorname{Pr}(\mathrm{p} 16+)$ was categorized into quintiles (Q1-Q5), and overall survival was compared with patients whose p16 status was known. Data from patients with known p16 status (the leave-one-out validation subset, $n=1282$ ) were used to assess the accuracy of various $\operatorname{Pr}(\mathrm{p} 16+)$ cut points (Appendix 4, available at www.cmaj.ca/lookup/suppl/doi:10.1503/cmaj $.161379 /-/ D C 1)$.

Time trends were determined using the year of diagnosis as the only predictor. We assessed overall survival by p16 status because we wanted to use survival characteristics as a method of externally assessing the appropriateness of our planned multiple imputation (i.e., because HPV status affects survival, imputed HPV status should affect survival in a similar fashion). The overall survival of patients with oropharyngeal cancer by p16 status was evaluated in the Toronto, Alberta (Edmonton and Calgary combined) and Halifax data sets, where reasonable proportions of patients' tumours underwent p16 testing.

\section{Sensitivity analysis}

Although imputation would allow generation of the change in the proportion of p16-positive patients over time with less missingness bias, assumptions associated with multiple imputation meant additional sensitivity analyses were necessary. We evaluated the sensitivity of time trends to differences in how p16 status was defined. The $\operatorname{Pr}(\mathrm{p} 16+)$ was plotted over time as both a continuous probability and as a proportion when patients were classified (dichotomized) with $85 \%$ sensitivity. We performed further analyses stratifying by province. These statistical procedures, as well as those described above, were performed using SAS version 9.4 (SAS Institute Inc.).

\section{Ethics approval}

Ethics approval was obtained from each institution's research ethics board, and the data were de-identified before being placed in the central database. 
Table 1 (part 1 of 2): Demographic, clinical and social characteristics of participants

Cancer centre; no. (\%) of patients*

\begin{tabular}{|c|c|c|c|c|c|c|}
\hline Characteristic & All & BC & Calgary & Edmonton & Toronto & Halifax \\
\hline Total no. & 3643 & 1085 & 402 & 336 & 1699 & 121 \\
\hline Mean no. patients/yr & - & 109 & 45 & 34 & 148 & 39 \\
\hline Catchment population, $\times 10^{6} \dagger$ & - & 4.113 & 1.645 & 1.645 & 4.753 & 0.913 \\
\hline Incidence $/ 10^{6}$ population & - & 27 & 27 & 21 & 31 & 43 \\
\hline Period of coverage & $2000-2012$ & $2001-2010$ & $2003-2011^{\star \star}$ & $2003-2012^{\star \star}$ & $2000-2012$ & 2009-2011 \\
\hline No. of new patients/yr, mean $\ddagger$ & - & 4.78 & 1.13 & 1.44 & 4.67 & 16.5 \\
\hline $\begin{array}{l}\text { No. of new p } 16+\text { patients/yr, } \\
\text { mean } ₫ \S\end{array}$ & - & 3.22 & 3.00 & 1.89 & 5.08 & 8.50 \\
\hline $\begin{array}{l}\text { Age at diagnosis, yr, } \\
\text { mean } \pm \text { SD }\end{array}$ & $60.4 \pm 10.7$ & $60.5 \pm 10.5$ & $59.6 \pm 10.9$ & $57.0 \pm 8.8$ & $61.0 \pm 11.0$ & $61.7 \pm 10.3$ \\
\hline \multicolumn{7}{|l|}{ Sex } \\
\hline Male & $2850(78)$ & $846(78)$ & $326(81)$ & $278(83)$ & $1304(77)$ & $96(79)$ \\
\hline Female & $793(22)$ & $239(22)$ & $76(19)$ & $58(17)$ & $395(23)$ & $25(21)$ \\
\hline Cancer subsite & $n=3428$ & $n=977$ & $n=377$ & $n=336$ & $n=1623$ & $n=114$ \\
\hline Tonsil & $1710(50)$ & $477(49)$ & $194(51)$ & $171(51)$ & $819(50)$ & $49(43)$ \\
\hline Base of tongue & $1271(37)$ & $397(41)$ & $152(40)$ & $131(39)$ & $526(32)$ & $65(57)$ \\
\hline Other & 447 (13) & $103(10)$ & $31(8)$ & $34(10)$ & $279(17)$ & $0(0)$ \\
\hline Primary treatment & $n=3606$ & $n=1085$ & $n=396$ & $n=336$ & $n=1672$ & $n=117$ \\
\hline Chemoradiotherapy & $1383(38)$ & $363(33)$ & $262(66)$ & $120(36)$ & $571(34)$ & $67(57)$ \\
\hline Radiation alone & $1060(29)$ & $466(43)$ & $65(16)$ & $9(3)$ & $498(29)$ & $22(19)$ \\
\hline Surgery + adjuvant & $885(25)$ & $170(16)$ & $27(7)$ & $187(56)$ & $487(29)$ & $14(12)$ \\
\hline Surgery alone & $170(5)$ & $35(3)$ & $20(5)$ & $20(6)$ & $81(5)$ & $14(12)$ \\
\hline No treatment & $108(3)$ & $51(5)$ & $22(6)$ & $0(0)$ & $35(2)$ & $0(0)$ \\
\hline Tumour $(\mathrm{T})$ stage & $n=3125$ & $n=734$ & $n=392$ & $n=333$ & $n=1547$ & $n=119$ \\
\hline 1 & $657(21)$ & $186(25)$ & $98(25)$ & $91(27)$ & $260(17)$ & $22(18)$ \\
\hline 2 & $1106(35)$ & $307(42)$ & $148(38)$ & $100(30)$ & $504(33)$ & $47(40)$ \\
\hline 3 & $733(24)$ & $165(22)$ & $50(13)$ & $84(25)$ & $408(26)$ & $26(22)$ \\
\hline 4 & $629(20)$ & $76(10)$ & $96(24)$ & $58(17)$ & 375 (24) & $24(20)$ \\
\hline Nodal (N) stage & $n=3149$ & $n=751$ & $n=391$ & $n=336$ & $n=1550$ & $n=121$ \\
\hline 0 & $596(19)$ & $178(24)$ & $73(19)$ & $24(7)$ & $303(20)$ & $18(15)$ \\
\hline 1 & 406 (13) & $108(14)$ & $57(14)$ & $53(16)$ & $178(11)$ & $10(8)$ \\
\hline 2 & $1898(60)$ & 397 (53) & $239(61)$ & $226(67)$ & $952(61)$ & $84(69)$ \\
\hline 3 & $249(8)$ & $68(9)$ & $22(6)$ & $33(10)$ & $117(8)$ & $9(8)$ \\
\hline TNM stage & $n=3157$ & $n=754$ & $n=396$ & $n=336$ & $n=1550$ & $n=121$ \\
\hline I & $119(4)$ & $36(5)$ & $18(5)$ & $1(<1)$ & $59(4)$ & $5(4)$ \\
\hline ॥ & $230(7)$ & $74(10)$ & $37(9)$ & $10(3)$ & $104(7)$ & $5(4)$ \\
\hline III & $495(16)$ & $153(20)$ & $54(14)$ & $55(16)$ & $221(14)$ & $12(10)$ \\
\hline IV & $2313(73)$ & $491(65)$ & $287(72)$ & $270(80)$ & $1166(75)$ & $99(82)$ \\
\hline Smoking status & $n=3563$ & $n=1028$ & $n=399$ & $n=336$ & $n=1686$ & $n=121$ \\
\hline Current & $1489(42)$ & $462(45)$ & $126(32)$ & $103(31)$ & $749(44)$ & $49(41)$ \\
\hline Former & $1319(37)$ & $377(37)$ & $168(42)$ & $156(48)$ & $567(34)$ & $51(42)$ \\
\hline Never & $755(21)$ & $191(18)$ & $105(26)$ & $68(21)$ & $370(22)$ & $21(17)$ \\
\hline $\begin{array}{l}\text { Pack-years among } \\
\text { ever-smokers, mean } \pm \text { SD }\end{array}$ & $32.9 \pm 25.6$ & $37.3 \pm 24.2$ & $33.0 \pm 23.3$ & $29.1 \pm 23.2$ & $31.8 \pm 21.1$ & $30.7 \pm 21.7$ \\
\hline
\end{tabular}


Table 1 (part 2 of 2): Demographic, clinical and social characteristics of participants

\begin{tabular}{|c|c|c|c|c|c|c|}
\hline \multirow[b]{2}{*}{ Characteristic } & \multicolumn{6}{|c|}{ Cancer centre; no. (\%) of patients ${ }^{*}$} \\
\hline & All & BC & Calgary & Edmonton & Toronto & Halifax \\
\hline Alcohol consumption & $n=3306$ & $n=874$ & $n=379$ & $n=325$ & $n=1607$ & $n=121$ \\
\hline None/light & $2032(61)$ & $540(62)$ & $277(73)$ & $205(63)$ & $913(57)$ & $97(80)$ \\
\hline Moderate/heavy & $1274(39)$ & $334(38)$ & $102(27)$ & $120(37)$ & $694(43)$ & $24(20)$ \\
\hline BMI, mean \pm SD & $26.7(6.90)$ & $26.5(5.23)$ & $26.2(5.42)$ & $27.5(5.02)$ & $26.8(9.44)$ & $27.0(5.59)$ \\
\hline Charlson comorbidity index & $n=2532$ & & $n=400$ & $n=336$ & $n=1675$ & $n=121$ \\
\hline 0 & $1327(52)$ & NA & $226(57)$ & $175(52)$ & $893(53)$ & $33(27)$ \\
\hline 1 & $703(28)$ & NA & $108(27)$ & $92(27)$ & $463(28)$ & $40(33)$ \\
\hline 2 & $305(12)$ & NA & $34(8)$ & $38(12)$ & $206(12)$ & $27(22)$ \\
\hline$\geq 3$ & $197(8)$ & NA & $32(8)$ & $31(9)$ & $113(7)$ & $21(18)$ \\
\hline Marital status & $n=3320$ & $n=798$ & $n=401$ & $n=336$ & $n=1665$ & $n=120$ \\
\hline Married & $2178(66)$ & $577(72)$ & $267(67)$ & $208(62)$ & $1037(62)$ & $89(74)$ \\
\hline Not married & $1142(34)$ & $221(28)$ & $134(33)$ & $128(38)$ & $628(38)$ & $31(26)$ \\
\hline Urbanization & $n=3635$ & $n=1080$ & $n=402$ & $n=336$ & $n=1697$ & $n=121$ \\
\hline Urban & $3078(85)$ & $896(83)$ & $348(87)$ & $270(80)$ & $1482(87)$ & $82(68)$ \\
\hline Rural & $557(15)$ & $184(17)$ & $53(13)$ & $66(20)$ & $215(13)$ & $39(32)$ \\
\hline p16 status & $n=3643$ & $n=1085$ & $n=402$ & $n=336$ & $n=1699$ & $n=121$ \\
\hline Tested & $1282(35)$ & $13(1)$ & $159(40)$ & $94(28)$ & $971(57)$ & $45(37)$ \\
\hline Positive & $946(74)$ & $11(85)$ & $127(80)$ & $79(84)$ & $692(71)$ & $37(82)$ \\
\hline Negative & $336(26)$ & $2(15)$ & $32(20)$ & $15(16)$ & 279 (29) & $8(18)$ \\
\hline $\begin{array}{l}\text { Note: BC = British Columbia (data fro } \\
\text { numbers), SD = standard deviation, } \\
\text { `Except where indicated otherwise. } \\
\text { †Population of catchment area in mi } \\
\text { population of Nova Scotia was used. } \\
\text { †Mean difference in the number of c } \\
\text { \$Restricted to those deemed to be } p \\
\text { IBased on the second digit of the Ca } \\
\text { **Edmonton and Calgary each captu } \\
\text { catchment for each of Edmonton an }\end{array}$ & $\begin{array}{l}\text { entres within th } \\
\text { tumour, lymph } \\
\text { of the range, ba } \\
\text { liagnosed in yea } \\
\text { sitive after mult } \\
\text { in postal code ( } \\
\text { out half of Alber } \\
\text { tary. For Toronto }\end{array}$ & $\begin{array}{l}\text { ritish Columbia } \\
\text { des and metast } \\
\text { minus the } 2006 \text { ce } \\
\text { imputation an } \\
\text { re } 0=\text { rural and } \\
\text { population, so }\end{array}$ & $\begin{array}{l}\text { cer Agency), BM } \\
\text { (cancer staging } \\
\text { sed Data for Halifa year } N- \\
\text { tegorization usi } \\
=\text { urban). } \\
\text { of the provincia }\end{array}$ & $\begin{array}{l}\text { ody mass index, } \\
\text { ver the entire pro } \\
\text { pulation from th } 85 \% \text { sensitivit }\end{array}$ & $\begin{array}{l}=\text { not applicabl } \\
\text { nce of Nova Scot } \\
\text { it point. } \\
06 \text { census was }\end{array}$ & $\begin{array}{l}\text { ecause of small } \\
\text { so the } \\
\text { as the }\end{array}$ \\
\hline
\end{tabular}

\section{Results}

\section{Patient population}

Of 3643 patients with oropharyngeal cancer, the mean follow-up time was 2.6 (standard deviation 2.3) years. Although the various centres each contributed data for a different period between 2000 and 2012, patients with oropharyngeal cancer had similar characteristics across centres (Table 1). Data from the 2 Alberta centres, which together covered the whole province, were combined for some of the subsequent analyses.

\section{p16 testing and testing bias over time}

p16 status was available from Toronto $(n=971$ [57\%]), Calgary $(n=159[40 \%])$, Edmonton $(n=94[28 \%])$ and Halifax $(n=45$ [37\%]), and the result was positive for most cases tested $(74 \%$; Table 1). Testing rates increased over time at all centres (Appendix 5, panel A, available at www.cmaj.ca/lookup/suppl/ doi:10.1503/cmaj.161379/-/DC1). Most recently, $88 \%$ of oropharyngeal cancers in Toronto were tested in 2012, 91\% in Edmonton in 2012 and 94\% in Calgary in 2011 (Appendix 5, panel A).
Despite routine testing in Halifax after 2009, p16 testing was unavailable for many patients; in these patients, the diagnosis was made from a fine-needle aspirate, which is not suitable for p16 staining.

In univariable analyses, p16 testing was more likely to occur if patients were younger, were male, had tumours of the tonsil or base of the tongue, never smoked, had fewer pack-years, had less alcohol consumption and had some nodal involvement ( $p<0.05$ for all; see Appendix 6, available at www.cmaj.ca/ lookup/suppl/doi:10.1503/cmaj.161379/-/DC1). After adjustment, p16 testing was more likely to be performed in males, lifetime never-smokers, patients with tonsillar or base-oftongue tumours and those with nodal involvement. Over time, testing for 16 status became less discriminatory by sex and tumour stage, yet some residual bias may have remained (Appendix 5, panels B to F)

Using a complete-case analysis, we observed no temporal change in the proportion of p16-positive cases of oropharyngeal cancer (Appendix 7, available at www.cmaj.ca/lookup/suppl/ doi:10.1503/cmaj.161379/-/DC1). 


\section{Modelling of p16 status}

Given the documented testing bias, we attempted to assign p16 status to untested patients using multiple imputation. Factors associated with p16-positive status included being younger, being male, having a tonsillar or base-of-tongue tumour, having lower tumour stage and any nodal involvement, lack of smoking history and lower alcohol consumption (none/light). These analyses were restricted to the Toronto and Alberta subsets because of the model's sample size constraints (Table 2).

The ability of social, demographic and clinical factors to predict p16 status is presented in Figure 1. The models that included age at diagnosis, sex, tumour classification, nodal classification, anatomic subsite, smoking status, smoking pack-years and alcohol consumption resulted in the highest $\mathrm{C}$ statistics (area under the curve). Neither body mass index (available only for Alberta patients) nor the Charlson comorbidity index improved the predictive ability of the models. Because of the small absolute number of patients from Halifax, a predictive model was not applied to this population.

\section{Overall survival by $\mathrm{p} 16$ status}

p16-negative status was consistently associated with worse overall survival in all centres. Overall survival of patients with oropharyngeal cancer by 16 status for the Toronto, Alberta and Halifax data sets is presented in Figure 2. According to a Cox propor-

Table 2: Clinical and demographic characteristics associated with p16 status in patients with known HPV status, combining data from Toronto and Alberta (Edmonton and Calgary)*

\begin{tabular}{|c|c|c|c|}
\hline \multirow[b]{2}{*}{ Characteristic } & \multicolumn{3}{|c|}{ Location; OR $(95 \% \mathrm{CI}) \dagger$} \\
\hline & $\begin{array}{c}\text { Toronto } \\
n=823 / 971 \ddagger\end{array}$ & $\begin{array}{c}\text { Alberta } \\
n=229 / 253 \ddagger \S\end{array}$ & $\begin{array}{l}\text { Toronto + Alberta } \\
n=1052 / 1224 \ddagger \subsetneq\end{array}$ \\
\hline Age at diagnosis, $\mathrm{yr}, \times 10$ & $0.64(0.52-0.78)$ & $0.62(0.37-1.05)$ & $0.64(0.53-0.77)$ \\
\hline \multicolumn{4}{|l|}{ Sex } \\
\hline Female & 1.00 (ref) & 1.00 (ref) & 1.00 (ref) \\
\hline Male & $1.90(1.20-3.02)$ & $4.38(1.26-15.3)$ & $2.13(1.39-3.25)$ \\
\hline \multicolumn{4}{|l|}{ Cancer subsite } \\
\hline Tonsil & 1.00 (ref) & 1.00 (ref) & 1.00 (ref) \\
\hline Base of tongue & $0.83(0.55-1.26)$ & $0.62(0.22-1.74)$ & $0.82(0.56-1.19)$ \\
\hline Other & $0.17(0.09-0.29)$ & $0.35(0.05-2.69)$ & $0.17(0.10-0.30)$ \\
\hline \multicolumn{4}{|l|}{ Tumour (T) stage } \\
\hline 4 & 1.00 (ref) & 1.00 (ref) & 1.00 (ref) \\
\hline 3 & $1.32(0.68-2.56)$ & $1.74(0.41-7.48)$ & $1.74(1.08-2.79)$ \\
\hline 2 & $1.35(0.83-2.19)$ & $6.27(1.75-22.5)$ & $1.76(1.14-2.72)$ \\
\hline 1 & $2.49(1.33-4.69)$ & $5.53(1.20-25.4)$ & $3.20(1.80-5.67)$ \\
\hline \multicolumn{4}{|l|}{ Nodal (N) stage } \\
\hline 0 & 1.00 (ref) & 1.00 (ref) & 1.00 (ref) \\
\hline 1 & $1.32(0.68-2.56)$ & $27.1(3.93-188)$ & $2.03(1.11-3.71)$ \\
\hline 2 & $2.31(1.40-3.80)$ & $14.6(3.08-69.5)$ & $2.84(1.78-4.53)$ \\
\hline 3 & $1.91(0.85-4.31)$ & $3.36(0.41-27.3)$ & $1.79(0.86-3.74)$ \\
\hline \multicolumn{4}{|l|}{ Smoking status } \\
\hline Current & 1.00 (ref) & 1.00 (ref) & 1.00 (ref) \\
\hline Former & $1.70(1.10-2.62)$ & $0.92(0.26-3.20)$ & $1.57(1.05-2.24)$ \\
\hline Never & $4.23(1.92-9.31)$ & $1.34(0.18-9.95)$ & $3.83(1.90-7.72)$ \\
\hline Pack-years, $\times 10$ & $0.90(0.83-0.96)$ & $0.68(0.49-0.94)$ & $0.88(0.81-0.94)$ \\
\hline \multicolumn{4}{|l|}{ Alcohol consumption } \\
\hline Moderate/heavy & 1.00 (ref) & 1.00 (ref) & 1.00 (ref) \\
\hline None/light & $2.55(1.70-3.83)$ & $3.70(1.27-10.8)$ & $2.61(1.80-3.78)$ \\
\hline \multicolumn{4}{|c|}{$\begin{array}{l}\text { Note: } \mathrm{Cl}=\text { confidence interval, } \mathrm{HPV}=\text { human papillomavirus, } \mathrm{OR}=\text { odds ratio. } \\
\text { *These analyses were restricted to the subsets for Toronto and Alberta because of the model's sample size requirements. } \\
\text { tFor comparison between p16-positive and p16-negative patients with oropharyngeal cancer. } \\
\text { fNumber analyzed/total sample (complete-case), adjusted for all variables in the table, } 1 \text { multivariable model per column. } \\
\text { §Additionally adjusted for site (Edmonton v. Calgary, } p=0.5) \text {. } \\
\text { ฯAdditionally adjusted for site (Edmonton and Calgary v. Toronto, } p=0.7 \text { ). }\end{array}$} \\
\hline
\end{tabular}


tional hazards regression model (stratified by province), the factors associated with poorer overall survival were older age, having a nontonsillar tumour, current smoking and having more advanced disease (Table 3). Even after adjustment for these factors, patients with p16-negative tumours had twice the risk of death relative to $\mathrm{p} 16$-positive patients.

Following multiple imputation, movement down each quintile of $\operatorname{Pr}(\mathrm{p} 16+)$, where Q5 was most likely to be p16-positive and Q1 was least likely to be p16-positive, was associated with an increase in mortality risk, with adjusted HR 1.58 (95\% Cl 1.511.66) per change in quintile (Figure $3 A$ ).

The optimal cut point (which maximized sensitivity and specificity) underestimated the p16-positive proportion of the validation subset (time 0; Appendix 8, available at www.cmaj.ca/lookup/ suppl/ doi:10.1503/cmaj.161379/-/DC1). However, lowering the $\operatorname{Pr}(\mathrm{p} 16+)$ cut point to yield a sensitivity of $85 \%$ resulted in nearly identical Kaplan-Meier plots between imputed and known p16 status in both the p16-positive and p16-negative strata, with $71 \%$ of the validation cohort being classified as p16-positive (Figure 3B, time 0$)$. This cut point corresponded to $\operatorname{Pr}(\mathrm{p} 16+)=68.7 \%$ and was used to categorize patients as p16-positive or p16-negative.

\section{Sensitivity analyses}

Under the continuous definition, the $\operatorname{Pr}(\mathrm{p} 16+)$ increased over time, from $61.8 \%$ in 2000 to $76.4 \%$ by 2012 ( $p<0.001$ ). When dichotomized (at the $85 \%$ sensitivity cut point definition), the proportion of p16-positive patients rose from $47.3 \%$ in 2000 to $73.7 \%$ in $2012(p<0.001)$ (Figure $4 \mathrm{~A})$.

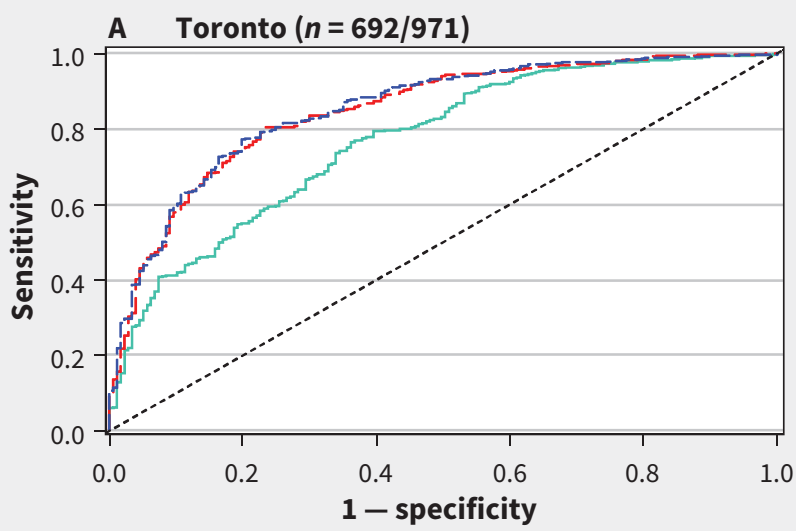

Model 1 (base model): $C=0.77(0.73-0.81)$
- - Model 2 (+ social habits): $C=0.85(0.81-0.88)$
-- Model 3 (+ social habits $+C \mathrm{Cl}): \mathrm{C}=0.85(0.82-0.88)$
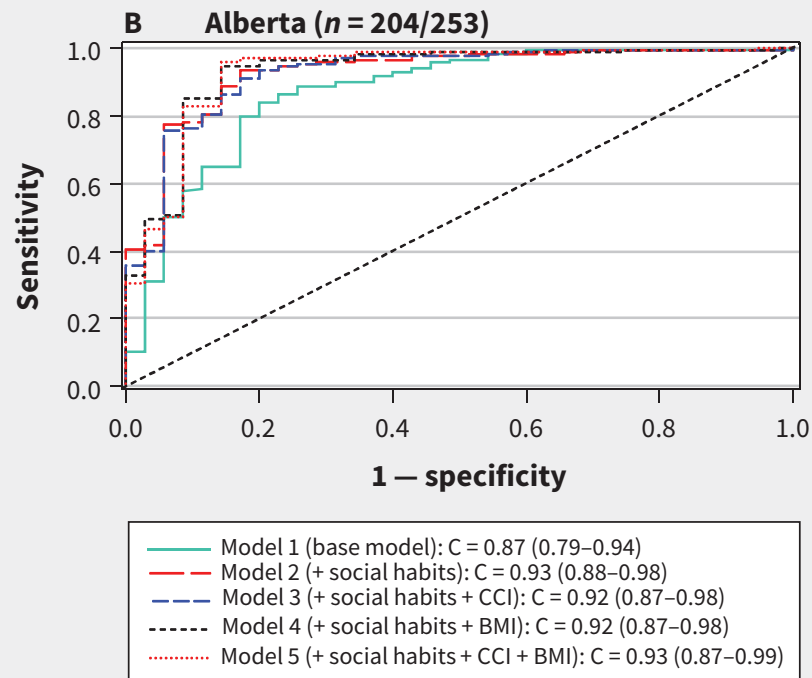
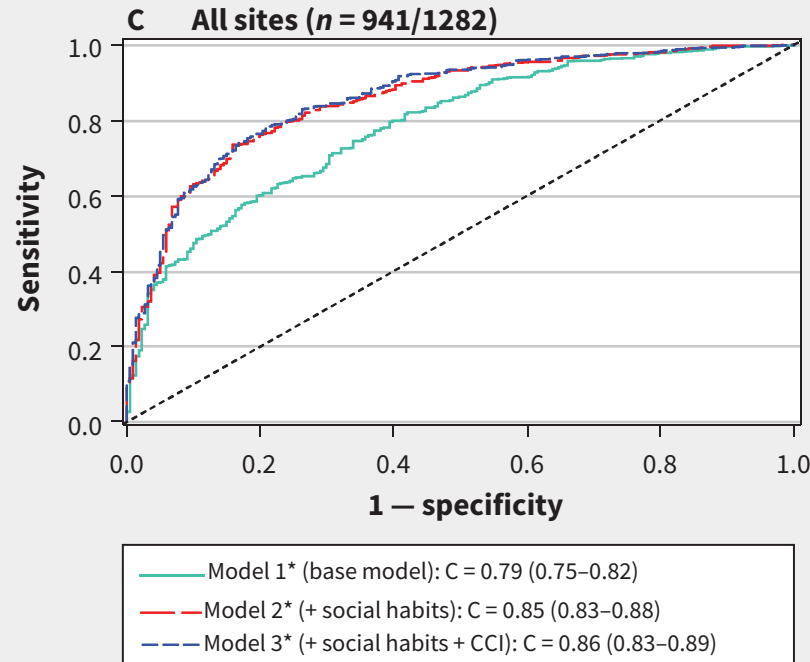

Figure 1: Receiver operating characteristic curves for prediction of p16 status using clinical and demographic variables. The area under the curve is represented by the $\mathrm{C}$ statistic (with 95\% confidence interval). The base model included age at diagnosis, sex, anatomic cancer subsite, tumour stage and nodal stage. Social habits included smoking status (current, former, never), smoking pack-years and alcohol consumption (none/light, moderate/heavy). Note: $\mathrm{BMI}=$ body mass index, $\mathrm{CCl}=$ Charlson comorbidity index. ${ }^{*}$ Model also includes province. 
The most robust rise in p16-positive oropharyngeal cancer was observed in Alberta, regardless of whether the $\operatorname{Pr}(\mathrm{p} 16+)$ was analyzed as a continuous variable (Figure 4B) or dichotomized with $85 \%$ sensitivity (Figure $4 \mathrm{C}$ ). For comparison, alternative cut points are presented, including the optimal cut point and cut points resulting in $90 \%$ sensitivity, $90 \%$ specificity and $85 \%$ specificity (Figure 4D). Regardless of the cut point chosen, by 2012 (when the fewest patients had p16 status imputed), the propor-
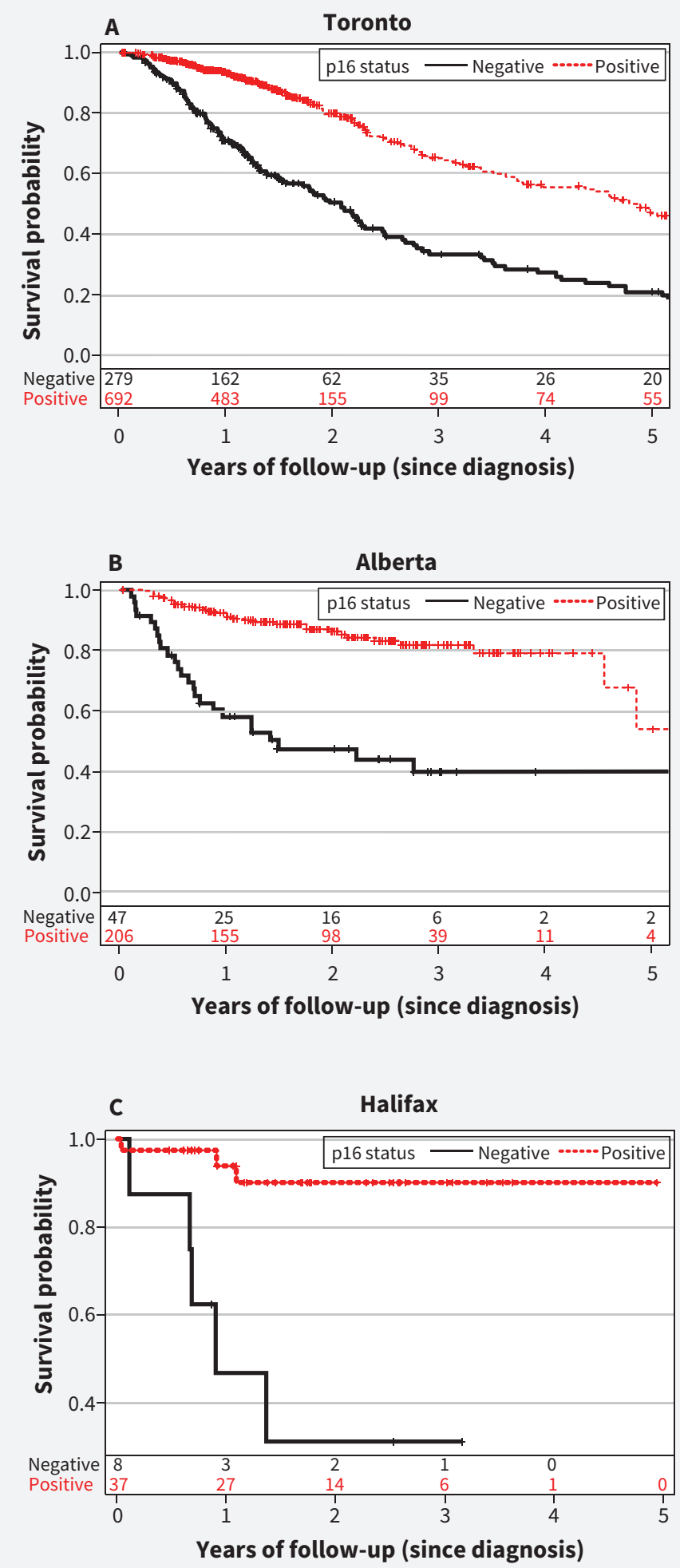

Figure 2: Overall survival, by p16 status, in Toronto, Alberta (Edmonton and Calgary combined) and Halifax. 
tion of p16-positive patients ranged from $71.0 \%$ (90\% specificity) to $76.4 \%$ (continuous probability). Similar results were obtained in a sensitivity analysis that excluded British Columbia and Halifax (since most of the data from these 2 locations were imputed; Appendix 9, available at www.cmaj.ca/lookup/suppl/doi :10.1503/cmaj.161379/-/DC1). Thus, regardless of the cut points used for imputation of p16-positive status, there was a clinically significant rise in the incidence of p16-positive oropharyngeal

Table 3: Factors associated with poorer overall survival in an analysis of patients with known HPV status, combining data from Toronto, Edmonton and Calgary (total $n=1282$ )

\section{$\mathrm{HR}(95 \% \mathrm{CI})$}

\begin{tabular}{|c|c|c|}
\hline Factor & Unadjusted & Adjusted* \\
\hline \multicolumn{3}{|l|}{ HPV status } \\
\hline Known positive & 1.00 (ref) & 1.00 (ref) \\
\hline Known negative & $3.03(2.44-3.76)$ & $2.16(1.67-2.79)$ \\
\hline Age at diagnosis, yr, $\times 10$ & $1.57(1.41-1.74)$ & $1.46(1.29-1.66)$ \\
\hline \multicolumn{3}{|l|}{ Sex } \\
\hline Female & 1.00 (ref) & 1.00 (ref) \\
\hline Male & $0.87(0.67-1.12)$ & $0.83(0.63-1.10)$ \\
\hline \multicolumn{3}{|l|}{ Cancer subsite } \\
\hline Tonsil & 1.00 (ref) & 1.00 (ref) \\
\hline Base of tongue & $1.31(1.03-1.67)$ & $1.30(1.01-1.66)$ \\
\hline Other & $2.16(1.58-2.94)$ & $1.56(1.12-2.17)$ \\
\hline \multicolumn{3}{|l|}{ Smoking status } \\
\hline Never & 1.00 (ref) & 1.00 (ref) \\
\hline Former & $1.71(1.20-2.44)$ & $1.16(0.79-1.71)$ \\
\hline Current & $2.99(2.15-4.17)$ & $2.00(1.33-3.01)$ \\
\hline Pack-years, $\times 10 \dagger$ & $1.12(1.08-1.15)$ & $1.02(0.97-1.06)$ \\
\hline \multicolumn{3}{|l|}{ Alcohol consumption $†$} \\
\hline None/light & 1.00 (ref) & 1.00 (ref) \\
\hline Moderate/heavy & $1.57(1.26-1.96)$ & $0.99(0.75-1.29)$ \\
\hline \multicolumn{3}{|l|}{ Tumour ( $\mathrm{T}$ ) stage } \\
\hline 1 & 1.00 (ref) & 1.00 (ref) \\
\hline 2 & $1.43(0.96-2.14)$ & $1.24(0.82-1.87)$ \\
\hline 3 & $2.28(1.52-3.42)$ & $1.64(1.08-2.50)$ \\
\hline 4 & $3.82(2.59-5.62)$ & $2.60(1.74-3.89)$ \\
\hline \multicolumn{3}{|l|}{ Nodal (N) stage } \\
\hline 0 & 1.00 (ref) & 1.00 (ref) \\
\hline 1 & $1.01(0.67-1.51)$ & $1.18(0.77-1.80)$ \\
\hline 2 & $0.97(0.72-1.31)$ & $2.03(1.45-2.86)$ \\
\hline 3 & $2.01(1.33-3.02)$ & $4.51(2.90-7.00)$ \\
\hline
\end{tabular}

Note: $\mathrm{Cl}$ = confidence interval, $\mathrm{HPV}=$ human papillomavirus, $\mathrm{HR}$ = hazard ratio ${ }^{\star}$ Adjusted for all variables in table and stratified by province, complete-case data $(n=1099 / 1282)$.

†Collinearity was not observed for smoking status or alcohol consumption. Removal of the pack-years variable only marginally changed the estimates for former smoking (HR $1.33,95 \% \mathrm{Cl}$ 0.92-1.93), current smoking (HR 2.35, 95\% Cl 1.62-3.42) and alcohol consumption (HR $1.02,95 \% \mathrm{Cl} 0.79-1.33$ ). cancer between 2000 and 2012. The rate of increase was greater for men than for women (Appendix 10, available at www.cmaj. ca/lookup/suppl/doi:10.1503/cmaj.161379/-/DC1).

\section{Interpretation}

We found an increase in the incidence of p16-positive oropharyngeal cancers as a proportion of all oropharyngeal squamous cell cancers between 2000 and 2012 among patients managed at specialist surgical centres across Canada. The rate of increase was greater for men than for women.

Selection bias occurs in HPV testing, and estimating changes in the incidence of p16-positive oropharyngeal cancer over time has therefore been difficult. Before implementation of routine HPV testing, clinicians were aware that additional testing created a burden for clinical laboratories, and thus reserved testing for those most likely to have HPV positivity. Only as accumulating data have supported the clinical importance of HPV testing has routine testing been implemented in most (though not all) Canadian centres. By imputing missing HPV status and finding different ways to validate our findings (Appendix 3), we were able to estimate that the prevalence of HPV-positive oropharyngeal cancer in 5 Canadian centres rose from about 47\% in 2000 to about $74 \%$ in 2012.

A recent systematic review reported that the rate of HPVpositive oropharyngeal cancer in North America plateaued at 65\% from 2005 to $2014 .^{5}$ However, a study in London, Ontario, was restricted to patients with tonsillar cancer for whom a pathology specimen was available; ${ }^{17}$ one study in Toronto included only 22 patients with oropharyngeal cancer; ${ }^{18}$ other Toronto-based studies either took place before routine HPV testing $^{12}$ or focused on recurrent or metastatic disease; ${ }^{19}$ and one study in Montréal analyzed patients with locally advanced cancer who were treated with primary chemoradiation and had a minimum 3-year follow-up. ${ }^{20} \mathrm{~A}$ previous study of 1374 Ontario-based patients with oropharyngeal cancer suggested that $66 \%$ of cases were HPV-positive by $2010 .{ }^{1}$ Given the limitations of these previous studies, a more comprehensive study across multiple Canadian centres was warranted.

HPV-positive oropharyngeal tumours differ from HPVnegative tumours with respect to etiology, histology and outcome, and we confirmed the need to test for HPV status as a routine diagnostic tool to differentiate these 2 distinct diseases. ${ }^{21}$ Given the potential health policy implications of these timetrend results, such as HPV vaccination for both sexes, we suggest that routine testing be accompanied by either routine supplemental coding (e.g., ICD or other system) or cancer registry annotation, so that HPV-positive and HPV-negative cases can be easily and separately tracked in Canada. Efforts to standardize HPV testing methods also warrant consideration.

We used multiple imputation to estimate the probability of HPV-positive status, given the known associations of demographic, clinical and social habits with HPV status ${ }^{22}$ (Appendix 3 ). Although some applications of multiple imputation are controversial, ${ }^{23}$ we used strongly predictive variables in this imputation. ${ }^{24}$ There is also evidence of the utility of imputation in data sets with large proportions of missing data. ${ }^{25,26}$ It is clear that 
without imputation, testing bias would affect the accuracy of results. ${ }^{22,27}$ We calibrated our results using survival data, which were external to the multiple imputation process, and performed leave-one-out internal cross-validation. Sensitivity analyses of the chosen cut point suggest a substantial rise over time. We cau- tion against overinterpreting the absolute values for the proportion of cases that were HPV-positive in the earlier years; however, our findings regarding a rise in proportion of HPV-positive oropharyngeal tumours are consistent with widespread clinical experience.
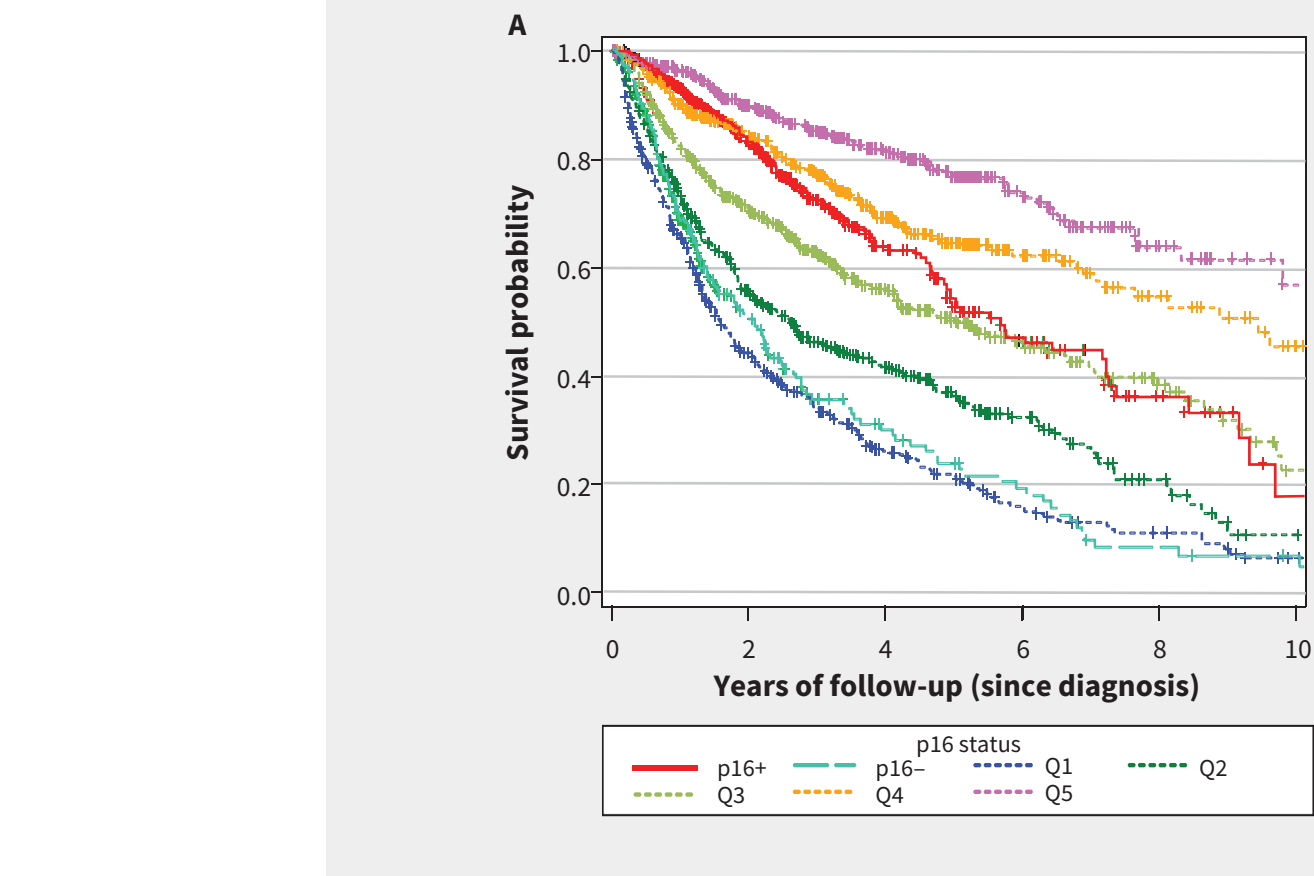

B
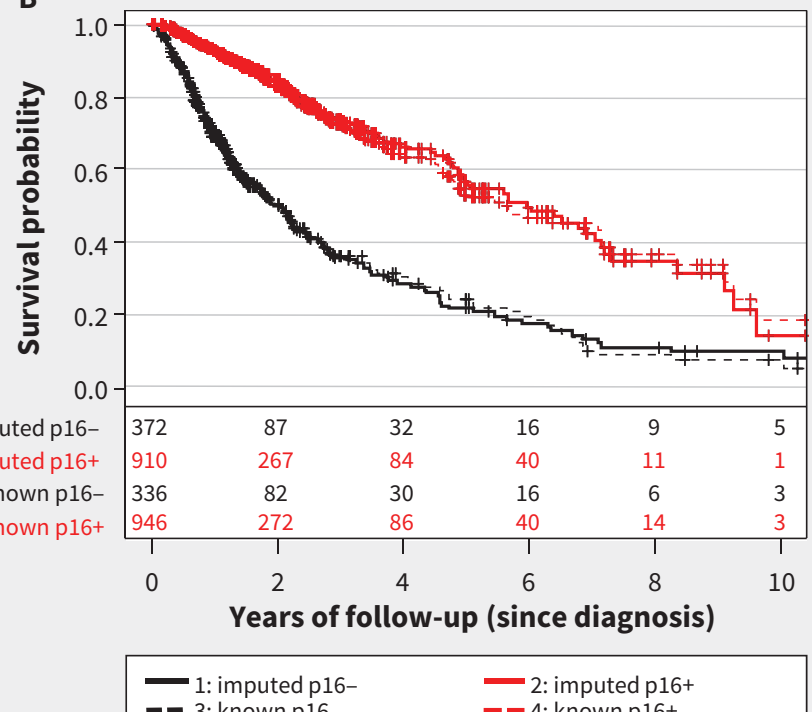

Figure 3: Overall survival by p16 status after multiple imputation. (A) For analysis of the entire cohort $(n=3643)$, the imputed population $(n=2361)$ was compared with the population having known p16 status ( $n=1282$ ). For the imputed population, the probability of p16-positive status, or $\operatorname{Pr}(\mathrm{p} 16+)$, was categorized into quintiles (Q5 = most likely to be $\mathrm{p} 16$-positive, $\mathrm{Q} 1=$ least likely to be p16-positive) and compared with patients with known p16 status. (B) The analysis was restricted to the validation subset (patients with known p16 status only; $n=1282$ ). Overall survival is presented by $\operatorname{Pr}(\mathrm{p} 16+)$ dichotomized with $85 \%$ sensitivity, where $\operatorname{Pr}(\mathrm{p} 16+)=68.7 \%$, and compared with the actual (i.e., tested) p16 status. 

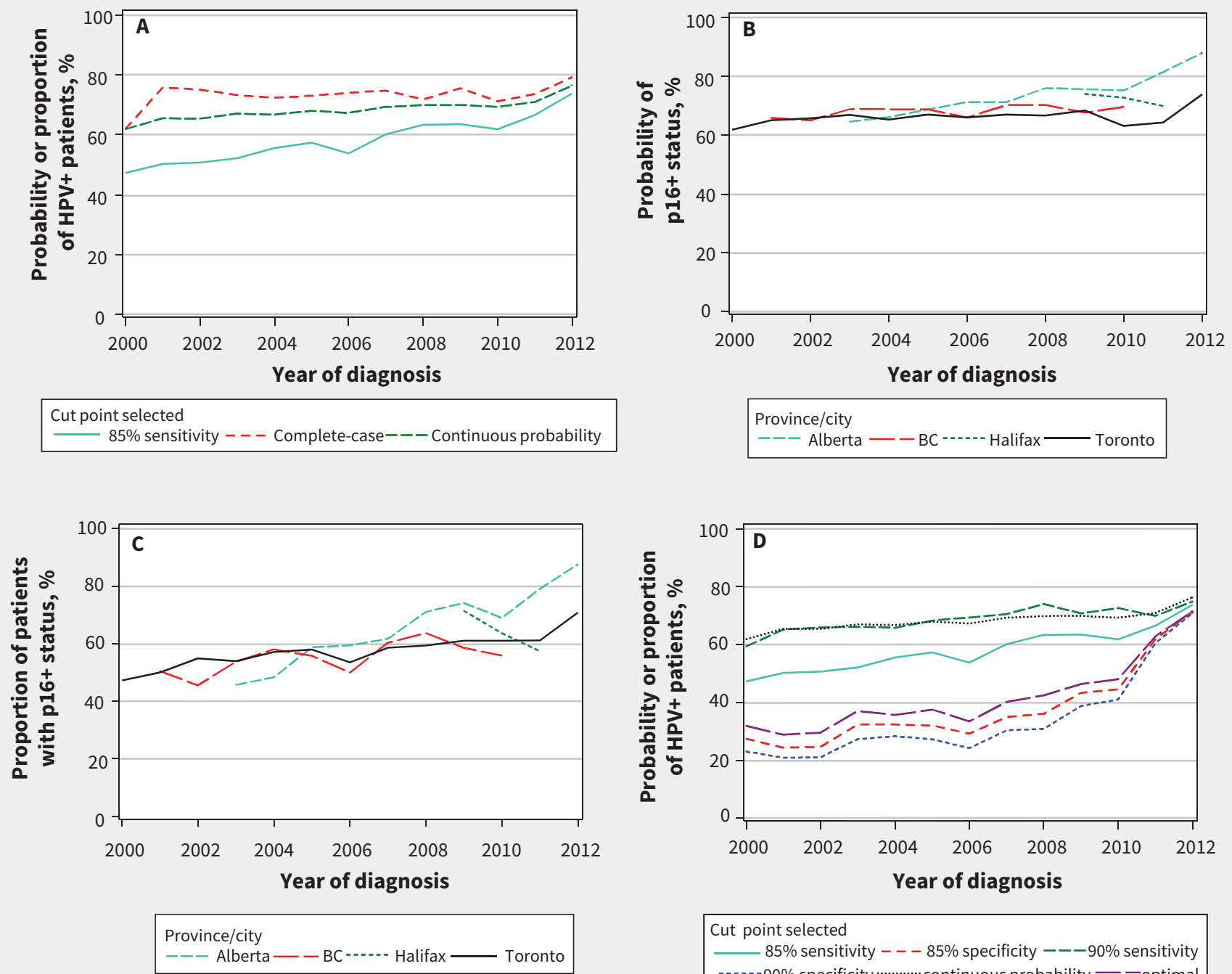

$\begin{aligned} & \text { Cut point selected } \\ & \text { 85\% sensitivity }---85 \% \text { specificity }---90 \% \text { sensitivity } \\ & -.--90 \% \text { specificity ………. continuous probability }--o p t i m a l\end{aligned}$

Figure 4: Change in p16-associated oropharyngeal cancer, following multiple imputation $(n=3643)$. (A) Probability and proportion of patients deemed positive for human papillomavirus (HPV), for all of Canada. Probability of p16-positive status, or $\operatorname{Pr}(\mathrm{p} 16+)$, was retained as a continuous probability or dichotomized with $85 \%$ sensitivity. The $\operatorname{Pr}(\mathrm{p} 16+)$ that resulted in $85 \%$ sensitivity was $68.7 \%$. (B) Probability of patients deemed HPV-positive, as mean continuous probability $\operatorname{Pr}(\mathrm{p} 16+)$ over time, stratified by cancer centre. (C) Proportion of patients deemed HPV-positive using a cut point with $85 \%$ sensitivity, stratified by cancer centre. (D) Probability and proportion of patients deemed HPV-positive, for all of Canada. The Pr(p16+) over time is shown with various cut points, and the data for "continuous probability" from Figure 4A superimposed for comparison. The optimal cut point resulted in a sensitivity of $71 \%$ and a specificity of $81 \%$.

\section{Limitations}

Data were not available from some parts of Canada; therefore, caution is urged in generalizing our findings to the entire Canadian population. One Quebec study estimated the prevalence of HPV-positive oropharyngeal cancer to be $43 \%$ ( $n=21$; 19972001), ${ }^{28}$ which does not reflect potential effects of recent high rates of HPV vaccination in Quebec. ${ }^{29}$ Cancer centres in several provinces (Manitoba, Saskatchewan, New Brunswick, Prince Edward Island, and Newfoundland and Labrador) and the territories were not represented in this analysis, but the absolute numbers of oropharyngeal cancer cases at these centres are small and unlikely to influence our conclusions. ${ }^{30} \mathrm{~A}$ further limitation of this study was the lack of information on sexual history, a wellrecognized risk factor for chronic HPV infection.

\section{Conclusion}

HPV-positive oropharyngeal cancer rates have risen across multiple Canadian centres. Although our findings are robust to sensitivity analysis, the rate of increase cannot be firmly determined because different assumptions lead to different slopes of the rise in HPV rates over time. To aid in a better understanding of disease heterogeneity and burden, cancer centres could try to collect risk factor data systematically (e.g., for smoking and alcohol consumption), and should strive to acquire tissue samples for 
HPV or p16 protein testing. Accurate estimates of the incidence of HPV-positive oropharyngeal cancer are needed to inform future health policy.

\section{References}

1. Habbous S, Chu KP, La Delfa A, et al. The changing incidence of human papillomavirus-associated oropharyngeal cancer using multiple imputation from 2000 to 2010 at a comprehensive cancer centre. Cancer Epidemiol 2013;37:820-9.

2. Weatherspoon DJ, Chattopadhyay A, Boroumand S, et al. Oral cavity and oropharyngeal cancer incidence trends and disparities in the United States: 20002010. Cancer Epidemiol 2015;39:497-504.

3. Castellsagué X, Alemany L, Quer M, et al.; ICO International HPV in Head and Neck Cancer Study Group. HPV involvement in head and neck cancers: comprehensive assessment of biomarkers in 3680 patients. J Natl Cancer Inst 2016;108:djv403.

4. Mehanna H, Beech T, Nicholson T, et al. Prevalence of human papillomavirus in oropharyngeal and nonoropharyngeal head and neck cancer - systematic review and meta-analysis of trends by time and region. Head Neck 2013;35:747-55.

5. Stein AP, Saha S, Kraninger JL, et al. Prevalence of human papillomavirus in oropharyngeal cancer: a systematic review. Cancer J 2015;21:138-46.

6. Forte T, Niu J, Lockwood GA, et al. Incidence trends in head and neck cancers and human papillomavirus (HPV)-associated oropharyngeal cancer in Canada, 1992-2009. Cancer Causes Control 2012;23:1343-8.

7. Shack L, Lau HY, Huang L, et al. Trends in the incidence of human papillomavirus-related noncervical and cervical cancers in Alberta, Canada: a population-based study. CMAJ Open 2014;2:E127-32.

8. Petrelli F, Sarti E, Barni S. Predictive value of human papillomavirus in oropharyngeal carcinoma treated with radiotherapy: an updated systematic review and meta-analysis of 30 trials. Head Neck 2014;36:750-9.

9. Owadally W, Hurt C, Timmins H, et al. PATHOS: a phase II/III trial of risk-stratified, reduced intensity adjuvant treatment in patients undergoing transoral surgery for human papillomavirus (HPV) positive oropharyngeal cancer. BMC Cancer 2015;15:602.

10. Samuels SE, Tao Y, Lyden T, et al. Comparisons of dysphagia and quality of life (QOL) in comparable patients with HPV-positive oropharyngeal cancer receiving chemo-irradiation or cetuximab-irradiation. Oral Oncol 2016;54:68-74.

11. Nevens D, Nuyts S. HPV-positive head and neck tumours, a distinct clinical entity. B-ENT 2015;11:81-7.

12. Shi W, Kato H, Perez-Ordonez B, et al. Comparative prognostic value of HPV16 E6 mRNA compared with in situ hybridization for human oropharyngeal squamous carcinoma. J Clin Oncol 2009;27:6213-21.

13. Agoston ES, Robinson SJ, Mehra KK, et al. Polymerase chain reaction detection of HPV in squamous carcinoma of the oropharynx. Am J Clin Pathol 2010; 134:36-41.
14. Liu SZ, Zandberg DP, Schumaker LM, et al. Correlation of p16 expression and HPV type with survival in oropharyngeal squamous cell cancer. Oral Oncol 2015;51:862-9.

15. Lau HY, Brar S, Klimowicz AC, et al. Prognostic significance of p16 in locally advanced squamous cell carcinoma of the head and neck treated with concurrent cisplatin and radiotherapy. Head Neck 2011;33:251-6.

16. Smeets SJ, Hesselink AT, Speel EJ, et al. A novel algorithm for reliable detection of human papillomavirus in paraffin embedded head and neck cancer specimen. Int J Cancer 2007;121:2465-72.

17. Nichols AC, Palma DA, Dhaliwal SS, et al. The epidemic of human papillomavirus and oropharyngeal cancer in a Canadian population. Curr Oncol 2013; 20:212-9.

18. Machado J, Reis PP, Zhang T, et al. Low prevalence of human papillomavirus in oral cavity carcinomas. Head Neck Oncol 2010;2:6

19. Chau NG, Perez-Ordonez B, Zhang K, et al. The association between EGFR variant III, HPV, p16, c-MET, EGFR gene copy number and response to EGFR inhibitors in patients with recurrent or metastatic squamous cell carcinoma of the head and neck. Head Neck Oncol 2011;3:11.

20. Thibaudeau E, Fortin B, Coutlée F, et al. HPV prevalence and prognostic value in a prospective cohort of 255 patients with locally advanced HNSCC: a singlecentre experience. Int J Otolaryngol 2013;2013:437815.

21. Truong Lam M, O'Sullivan B, Gullane P, et al. Challenges in establishing the diagnosis of human papillomavirus-related oropharyngeal carcinoma. Laryngoscope 2016;126:2270-5.

22. Sterne JA, White IR, Carlin JB, et al. Multiple imputation for missing data in epidemiological and clinical research: potential and pitfalls. BMJ 2009;338:b2393.

23. Dong Y, Peng CY. Principled missing data methods for researchers. Springerplus 2013;2:222.

24. Hardt J, Herke M, Leonhart R. Auxiliary variables in multiple imputation in regression with missing $X$ : a warning against including too many in small sample research. BMC Med Res Methodol 2012;12:184.

25. Mishra S, Khare D. On comparative performance of multiple imputation methods for moderate to large proportions of missing data in clinical trials: a simulation study. J Med Stat Inform 2014;2:9.

26. Lee KJ, Carlin JB. Recovery of information from multiple imputation: a simulation study. Emerg Themes Epidemiol 2012;9:3.

27. White IR, Carlin JB. Bias and efficiency of multiple imputation compared with complete-case analysis for missing covariate values. Stat Med 2010;29:2920-31.

28. Pintos J, Black MJ, Sadeghi N, et al. Human papillomavirus infection and oral cancer: a case-control study in Montreal, Canada. Oral Oncol 2008;44:242-50.

29. Drolet M, Deeks SL, Kliewer E, et al. Can high overall human papillomavirus vaccination coverage hide sociodemographic inequalities? An ecological analysis in Canada. Vaccine 2016;34:1874-80.

30. Table 103-0553: New cases and 1991 age-standardized rate for primary cancer (based on the August 2015 CCR tabulation file), by cancer type and sex, Canada, provinces and territories. Ottawa: Statistics Canada; 2016. Available: www5. statcan.gc.ca/cansim/ (accessed 2016 June 6).

\section{Competing interests: None declared.}

This article has been peer reviewed.

Affiliations: Ontario Cancer Institute (Habbous, O'Sullivan, Huang, Liu) and Department of Biostatistics (Xu), Princess Margaret Cancer Centre, Toronto, Ont.; Radiation Oncology (Chu, Belayneh, Parliament), Cross Cancer Institute, Edmonton, Alta.; Department of Oncology (Lau, Hao), University of Calgary, Alberta Health Services, Calgary, Alta.; Department of Oncology (Schorr, Hao), Division of Medical Oncology, Tom Baker Cancer Centre, Calgary, Alta.; Division of Medical Oncology (Ha, Murray, Snow), Nova Scotia Cancer Centre, Dalhousie University, Halifax, NS; Department of Radiation Oncology (O'Sullivan, Huang), Department of Medicine (Liu) and Department of Epidemiology, Dalla Lana School of Public Health (Liu), University of Toronto, Toronto, Ont.; Medical Oncology (Cheung), BC Cancer Agency, Vancouver, BC
Contributors: Steven Habbous, Karen Chu, Stephanie Snow, Matthew Parliament, Desiree Hao, Winson Cheung, Wei Xu, Geoffrey Liu and Brian O'Sullivan contributed to the concept and design of the work. Steven Habbous, Karen Chu, Harold Lau, Melissa Schorr, Mathieos Belayneh, Michael Ha, Scott Murray, and Shao Huang acquired the data. Steven Habbous, Wei Xu and Geoffrey Liu analyzed the data, and all of the authors contributed to interpreting the data. Steven Habbous and Geoffrey Liu drafted the manuscript. All of the authors revised the manuscript for important intellectual content, approved the final version of the manuscript and agreed to act as guarantors of the work.

Funding: The Princess Margaret Hospital Head and Neck Cancer Translational Research Program is funded by the Wharton family, Joe's Team, Gordon Tozer, Bruce Galloway and the Elia family. Geoffrey Liu was sup- ported by the Posluns Family Fund and the Lusi Wong Family Fund at the Princess Margaret Foundation, the Alan B. Brown Chair in Molecular Genomics and the Cancer Care Ontario Chair in Experimental Therapeutics and Population Studies. This analysis was further supported by an operating grant from the Canadian Cancer Society Research Institute. The funders had no role in this research.

Acknowledgements: The authors thank Maryam Mirshams, Kevin Boyd, Qin Kong and Colleen Simpson for data support.

Accepted: Mar. 9, 2017

Correspondence to: Geoffrey Liu, geoffrey. liu@uhn.ca and Steven Habbous, steven_ habbous@hotmail.com 